\title{
La memoria y la enseñanza de la violencia política desde estrategias audiovisuales*
}

Memory and Teaching of Political Violence Using Audiovisual Strategies

A memória e o ensino da violência política desde estratégias audiovisuais

\section{Diego H. Arias Gómez** iD orcid.org/0000-0002-0116-0896}

\author{
Artículo de investigación \\ Revista Colombiana de Educación, N. 71. Segundo semestre de 2016, Bogotá, Colombia. \\ Para citar: Arias, D. H. (2016). La memoria y la enseñanza de la violencia política \\ desde estrategias audiovisuales. Revista Colombiana de Educación, (71), 253-278.
}

\section{Recibido: $23 / 11 / 15$ \\ Evaluado: 03/03/16 \\ $06 / 04 / 16$}

* El presente artículo está escrito en el marco de la investigación "Perspectivas docentes sobre enseñanza de la historia reciente en Colombia", código 2-7-535-16, financiado por el CIDC de la Universidad Distrital.

** Licenciado en filosofía de la Universidad Santo Tomás. Magíster en Sociología de la educación de la Universidad Pedagógica Nacional. Doctor de Educación de la misma universidad. Actualmente es docente asociado de la Facultad de Ciencias y Educación de la Universidad Distrita Francisco José de Caldas. Miembro del Grupos de Investigación Educación y Cultura Política. Correo: diegoarias8@gmail.com 


\section{Resumen}

Dado el creciente interés que suscita en el país y en la región el tema del conflicto político y armado que ha vivido Colombia durante las últimas décadas, sobre todo en relación con su tratamiento en la escuela y específicamente con los recursos didácticos que se han utilizado para trabajar con estudiantes de Educación Básica, el presente artículo se propone establecer unas posibles estrategias didácticas para el abordaje de la enseñanza de la historia reciente en el aula, concretamente desde elementos audiovisuales. Para ello, inicialmente se conceptualiza sobre temas como la memoria, la enseñanza de la historia reciente, se pasa luego a los usos del cine y del documental políticos en el aula y se finaliza con algunos aportes pedagógicos para abordar este sensible tema con estrategias audiovisuales.

\section{Palabras clave}

enseñanza de la historia reciente; pedagogía de la

memoria; enseñanza del

conflicto; historia reciente; pasado reciente

\section{Keywords}

teaching recent history; memory pedagogy; teaching of conflict; recent history; recent past

\begin{abstract}
Given the growing interest in the country and the region in the Colombian political and armed conflict during the last decades, especially in relation to his treatment at school and specifically to the teaching resources that have been used to work with elementary school students, the purpose of this article is to establish possible teaching strategies for addressing the teaching of recent history in the classroom, particularly through the use of audiovisual elements. To do this, initially there is a conceptualization on topics such as memory and the teaching of recent history. Then, the article exposes the uses of film and political documentary in the classroom, and ends with some pedagogical contributions to address this sensitive issue by applying audiovisual strategies.
\end{abstract}

\section{Resumo}

Dado o crescente interesse que suscita no país e na região o tema do conflito político e armado que tem vivido Colômbia durante as últimas décadas, principalmente em ralação com seu tratamento na escola e especificamente com os recursos didáticos que tem utilizado para trabalhar com estudantes de Educação Básica, o presente artigo se propõe estabelecer umas possíveis estratégias didáticas para a abordagem do ensino da história recente na sala, concretamente desde elementos audiovisuais. Para este efeito, inicialmente se conceitua sobre temas como a memória, o ensino da história recente, para logo passar aos usos do cinema e dos documentais políticos na sala e termina com alguns aportes pedagógicos para abordar neste tópico com algumas estratégias audiovisuais.

\section{Palavras chave}

ensino da história recente pedagogia da memória; ensino do conflito; história recente; passado recente 
La emancipación, por su parte, comienza cuando se vuelve a cuestionar la posición entre mirar y actuar, cuando se comprende que las evidencias que estructuran de esa manera las relaciones del decir, del ver y del hacer pertenecen, ellas mismas, a la estructura de la dominación y de la sujeción. Comienza cuando se comprende que mirar es también una acción que confirma o que transforma esta distribución de las posiciones. El espectador también actúa, como el alumno o como el docto. Observa, selecciona, compara, interpreta.

J. Rancière,

El espectador emancipado

\begin{abstract}
Educar la mirada es luchar contra la ceguera, pero no contra esa ceguera que es simple ausencia de imágenes, incapacidad o imposibilidad de ver, sino contra esa ceguera que nos imponen

las imágenes masivas del poder, esa ceguera que es también

y sobre todo mental, y eso solo puede hacerse produciendo otras imágenes, atendiendo a otras imágenes, produciendo otra relación entre las imágenes y el pensamiento.
\end{abstract}

J. Larrosa,

Niños atravesando el paisaje

\title{
Introducción
}

E n un sugerente libro titulado El olor del humo. Auschwitz y la pedagogía del exterminio, el escritor italiano Raffaele Mantegazza (2006) abre su reflexión narrando una reciente experiencia en una visita a las instalaciones de lo que fue un campo de concentración en Alemania, donde observa un grupo de estudiantes que probablemente se ganaron el viaje por un trabajo escolar sobre el tema de la Shoah. Estos estudiantes se divierten, juegan, uno de ellos finge subir la alambrada y electrocutarse. El autor cuenta que al terminar la visita, ya en el restaurante, un muchacho dice con burla que la chimenea está encendida y se pregunta si servirán carne de judío. Ante esta situación Matengazza (2006) hace algunas reflexiones para sí mismo y se reprocha el no haber reaccionado a tiempo frente a estos jóvenes inconscientes, que si bien parecían buenos estudiantes, no racistas, no nazis, presentaban una actitud indolente ante una tragedia ajena. El autor termina la introducción al libro, que enmarca esta historia, escribiendo que le habría gustado dar una cachetada no solo a aquel chico, sino, sobre todo, "a nosotros, los adultos, por no haber sabido enseñarle a ese adolescente cuándo Ilorar y reír y cómo comportarse cuando se visita un campo de exterminio" (p. 10). Su libro, aunque tardío dice el autor, quiere ser esa bofetada que haga que el mal no germine. 
Estas palabras ponen sobre el tapete la importancia de la educación frente a los procesos de barbarie acaecidos en las sociedades, principalmente para aquellos destinatarios que no han padecido de manera directa las implicaciones de las catástrofes. ¿Cómo transmitir el dolor de las víctimas? ¿Cómo educar -al decir de Adorno (1998)- para que la barbarie no se repita? ¿Cómo sensibilizar subjetividades aparentemente anestesiadas y apáticas?

Escribe Forges (2006) que Hitler, pese a ser derrotado ganó la guerra porque la barbarie tuvo nuevos capítulos, como lo confirman las masacres de Bosnia, Ruanda y las dictaduras de América Latina, entre otras; por ello, continúa el autor, "el proyecto de enseñar la realidad de los campos y de la Shoah es indispensable para mantener la memoria, única pero débil oportunidad que tenemos para protegernos contra el regreso del horror" (p. 15). En tal sentido, cree el autor, es difícil la formación en la conciencia ética de las nuevas generaciones por los riesgos de caer en la banalidad y en la sensiblería ante dolor, lo que no afecta la conciencia. Ciertamente, el peso de un pasado traumático en las generaciones que no vivieron la crudeza de algunos sucesos y que lo ven distante en el tiempo, puede devenir en la repetición hueca y en la ritualización banal (Jelin y Lorenz, 2004).

Los programas escolares pueden abordar la semejanza entre las víctimas de tragedias presentes y pretéritas, pero no deben olvidar la singularidad de cada masacre. Hay que mostrar la complejidad de las causas de los crímenes en los ámbitos político, económico, social e intelectual. Pero las actividades escolares deben también subrayar las resistencias y los actos de salvamento que dirigieron a la humanidad en la lucha contra la barbarie. Así lo previene Forgues (2006):

Pero la rapidez con la cual los seres humanos basculan en la barbarie es aterradora. Lo hemos visto en Yugoslavia, en Rwanda, en Argelia. Entre nosotros duerme una potencia bestial que puede desencadenarse con el primer pretexto que venga, ya sea político, étnico o religioso. Sin duda muchos SS sintieron placer haciendo Auschwitz y no dudo que, entre las razones de los horrores de la Argelia de los años noventa, esté el atroz placer de los torturadores y de los degolladores. Por ello educar contra Auschwitz significa combatir sin descanso la más mínima tolerancia a la más mínima humillación, a la más mínima discriminación, al más mínimo aprendizaje del mínimo placer sádico. Primo Levi nos ha enseñado que el camino hacia el Lager se recorre rápido, que la humanidad ya estuvo allí, que regresará de nuevo allí algún día y que será necesario aún estar, "de nuevo, con el estado de ánimo no para hablar del fascismo, sino para luchar contra él". El deber de memoria solo tiene sentido si conduce a la movilización, a la vigilancia y a la resistencia ante el presente y el futuro (p. 250). 


\section{Los asuntos de las memorias}

Según Huyssen (2002) los discursos de la memoria en las ciencias humanas y sociales, si bien se pueden rastrear en los pioneros trabajos de Halbachws y Nora desde principios del siglo $x \mathrm{x}$, adquieren fuerza en occidente a partir de la década de 1960 producto de los nuevos movimientos sociales y de los procesos de descolonización que reivindicaron versiones alternativas de la historia. Adicionalmente, según el autor, esta oleada se intensifica desde comienzos de la década de 1980, sobre todo en Estados Unidos y Europa, al tenor de los debates y las conmemoraciones que se dan respecto al Holocausto y la Segunda Guerra Mundial. Para este periodo, este resurgimiento se conecta en América Latina con los procesos de transición a la democracia luego de los nefastos regímenes dictatoriales que padecieron algunos países del continente durante largos años.

Huyssen (2002) acuña el concepto de globalización de la memoria para referirse al auge que la memoria, con todos sus matices, logra en el mundo académico y cultural al finalizar el siglo xx. Y agrega dos vertientes a esta dinámica: por un lado el sentido común que asume el Holocausto como fracaso del proyecto de la llustración, en el entendido de mostrar la incapacidad de la civilización de vivir con ciertas oposiciones; y por otro, el surgimiento del Holocausto como núcleo universal de la memoria implica el resalte de acontecimientos locales que, aunque distantes en el tiempo y el espacio, se vinculan a aquel. En palabras del autor, "el Holocausto devenido tropos universal es el requisito previo para descentrarlo y utilizarlo como un poderoso prisma a través del cual podemos percibir otros genocidios" (p. 18). El reconocimiento global del Holocausto como expresión máxima de la maldad contra grupos humanos es usado por poblaciones que padecen o padecieron la tortura y la muerte, para provocar la visibilidad de su drama y la solidaridad con su causa en otras latitudes.

Por su parte Jaramillo (2011) ubica este revival de la memoria en la larga tradición teórica que impugna el positivismo y la rígida división entre sujeto-objeto que por mucho tiempo imperó en la investigación social; en concreto, destaca al giro de las ciencias sociales de la segunda mitad del siglo $x x$ hacia perspectivas interdisciplinares y posmodernas. Para el autor, este viraje al pasado también tiene su correlato en las corrientes historiográficas que recusan las visiones totalitarias y universalistas. En esta misma línea, Erice (2008) considera que las nuevas connotaciones de la memoria obedecen a un triple giro: el subjetivo, el lingüístico y el hermenéutico, movimiento que confluye en una fuerte valoración de las narrativas que dan cuenta de la identidad de las personas, de las microhistorias por mucho tiempo invisibilizadas y de la legitimidad dada a

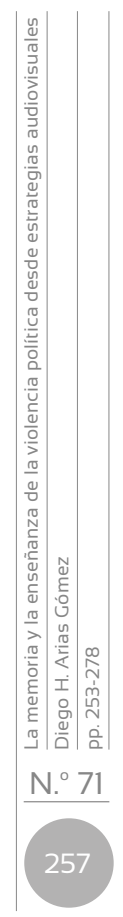


las interpretaciones literarias y ficcionales antes desechadas en el ámbito académico por inverosímiles. Este último aspecto coincide con los postulados de Ricoeur (2000) respecto a la interdependencia que guardan la historia y la memoria, que, aunque corresponden a regímenes de conocimiento distintos, según el autor se retroalimentan en la línea del tiempo que configuran históricamente las sociedades y que por tanto constituye lo humano.

Volviendo a Huyssen (2002), este surgimiento de la memoria no puede entenderse al margen de las industrias culturales y del marketing que provoca esta nueva mirada sobre los sucesos del pasado. Más allá de los juicios que estigmatizan determinadas producciones audiovisuales por inauténticas o ficcionales, lo cierto es que el mundo se ha musealizado y todas las esferas de lo social han ocupado un lugar en este posicionamiento. Por ello, el autor también habla de cultura de la memoria, para expresar esta dinámica cuyo contenido en ciertas naciones ha tenido un tinte más político que en otras, por efecto de los pasados traumáticos que padecieron, como es el caso de la Europa del Este, la ex Unión Soviética, Sudáfrica o las sociedades posdictatoriales de América Latina.

Así, es posible afirmar con Traverzo (2012) que la memoria al ser una representación del pasado que se rehace en el presente, es dinámica, pues en ella confluyen distintas fuerzas modificadas por el tiempo y filtradas por muchas experiencias acumuladas. Las memorias, al ser una construcción social, cambian no solo dependiendo de los sujetos que las enuncian, sino de los contextos que hacen posible tal enunciación. Este planteamiento pone en evidencia que la memoria no es neutra (Calveiro, 2006; Jelin, 2006), y que la aparición de las disputas por la memoria hace de ella una herramienta de lucha de ciertos sectores sociales en su reclamo por justicia y verdad frente a crímenes cometidos. En esta misma línea argumental, para Cuesta (2014),

\begin{abstract}
Ahí se plasma la tardía y "contramoderna" metamorfosis conceptual del término memoria, mutación estratégica en la revisión crítica de la modernidad, que consistió en la reconversión de una facultad individual (una potencia del alma al servicio de la prudencia), y una artificiosa tecnología del recuerdo cada vez más desvinculada de la ciencia de la historia, en herramienta cognitiva, hermenéutica y ética de primer orden con vistas a develar la racionalidad del mundo social del capitalismo y sus justificaciones ideológicas (p. 17).
\end{abstract}

En consonancia con este planteamiento, Lomas (2011) cree que los trabajos sobre la memoria social tienen gran relevancia ya que con ella se hace visible lo invisible, pues 
un deber de justicia con las víctimas de tantas imposturas, de tantos silencios, de tantos maltratos, de tantos exilios y de tantas diásporas, de tantas cárceles, de tantas torturas y de tantas muertes (p. 11).

Estas apuestas ponen de manifiesto el carácter político de la memoria, ya que su delineamiento se inscribe frontalmente en la lucha por un orden social deseado (Lechner, 2002).

Recogiendo el anterior sentido, el presente escrito se suscribe a esa acepción de la memoria, bajo la consideración de que la memoria se halla en permanente tensión entre varios intereses políticos que tratan de imponerle significado, esto es, de legitimar no solo ciertas versiones del pasado, sino de darle mayor protagonismo a determinadas lógicas en desmedro de otras versiones, otras víctimas y otros victimarios. En términos de Jelin (2005), "la lucha por el sentido del pasado se da en función de la lucha política presente y los proyectos de futuro" (p. 229). Por ello, es más que pertinente hablar de memorias en plural, que se arman no como un rompecabezas, sino como un lego,

dando la posibilidad de colocar las mismas piezas en distintas posiciones, para armar con ellas no una misma figura sino representaciones diferentes cada vez. Es por ello que, en esta clase de construcción, no puede haber un relato único ni mucho menos dueños de la memoria (Calveiro, 2006, p. 378).

\section{El pasado reciente, usos y abusos en la escuela}

Es lugar común el afirmar que la escuela ha desempeñado un lugar estratégico en la invención de la tradición (Hobsbawm y Ranger, 1983), entendida como la creación de un relato que aglutina sentimientos, concepciones y símbolos que, a fuerza de repetición, tienden a naturalizarse y reproducirse. Bajo esta guisa, la escuela ha ofrecido un abanico de recursos morales e ideológicos para que las nuevas generaciones se sintieran vinculadas al Estado-nación (Anderson, 1993; Arias, 2015a; Del Pozo, 2000; Herrera, Pinilla y Suaza, 2003), ello explica el predominio durante mucho tiempo de currículos patrioteros, románticos y naturalistas, cuyo énfasis estaba puesto más que en el conocimiento del mundo, en el amor que se le debía profesar a la patria (Carretero y Kriger, 2004).

En las últimas décadas, no solo se ha replanteado la antigua función identitaria de la escuela y de la enseñanza de las ciencias sociales en particular, por cuanto otros propósitos, atados a las demandas de la globalización, interpelan los contenidos curriculares, especialmente de las ciencias sociales y la historia escolares. Así, surgen temas sobre la ecología, la ciudadanía, los derechos humanos y los sujetos sociales, entre otros, que incomodan las antiguas prescripciones escolares centradas 
en contenidos lejanos y ciertamente distantes en el tiempo y el espacio. También, con creciente interés, la escuela y sus profesores son abocados a incorporar acontecimientos de reciente ocurrencia, en concreto, a trabajar en el aula eventos traumáticos de carácter político que afectaron radicalmente la historia de su nación. Dicha intromisión en las aulas del pasado cercano no ha estado exenta de debate y ha puesto en evidencia los legendarios combates por la definición de los contenidos dignos de ser enseñados. Para Cuesta (2014), el tema de la memoria y de la enseñanza de la historia reciente han de ubicarse en la impugnación al modelo de la razón ilustrada, en el sentido de propender por la transformación social desde el posicionamiento, en la escuela y fuera de ella, de las versiones de los vencidos. En este mismo sentido, Herrera y Vélez (2014) consideran que los registros de la violencia política introducidos en la escuela tensionan y desestabilizan las prácticas educativas tradicionales y los modos de formación política presentes en ella.

Punto clave en esta construcción lo ha representado la celebración de las efemérides, que articulan, como pocos ritos cívicos, esa fusión entre la glorificación de un pasado remoto o cercano y los propósitos escolares (Caldo, 2014). En América Latina, en los últimos años, las viejas fechas de la independencia vienen siendo complementadas o sobrepuestas a nuevos días en el calendario que rememoran hitos referidos a inicios o terminaciones de dictaduras, acontecimientos emblemáticos o graves violaciones a los derechos humanos, entre otros.

En Colombia, la normativa escolar sobre la enseñanza de la violencia política de las últimas décadas también es reciente. Ella se materializa en los estándares de competencias ciudadanas (MEN, 2004a) y sobre todo en los estándares básicos de ciencias sociales (MEN, 2004b). Estos últimos pretenden regular el currículo para el área de ciencias sociales e historia en las escuelas del país, y estipulan ciertas generalidades sobre contenidos y actitudes a inculcar en la educación básica. Específicamente estos estándares, que están separados por ciclos de dos o tres grados de $1^{\circ}$ a $11^{\circ}$, puntualiza para los grados $10^{\circ}$ y $11^{\circ}$ los siguientes enunciados alusivos a la historia reciente:

» Analizo el periodo conocido como "la violencia" y establezco relaciones con las formas actuales de violencia.

» Identifico las causas, características y consecuencias del Frente Nacional.

» Explico el surgimiento de la guerrilla, el paramilitarismo y el narcotráfico en Colombia. [...]

» Describo el impacto de hechos políticos de mediados del siglo xx (9 de abril, Frente Nacional...) en las organizaciones sociales, políticas y económicas del país. 
» Reconozco y explico los cambios y continuidades en los movimientos guerrilleros en Colombia desde su surgimiento hasta la actualidad.

»Identifico causas y consecuencias de los procesos de desplazamiento forzado de poblaciones y reconozco los derechos que protegen a estas personas. [...]

» Asumo una posición crítica frente a las acciones violentas de los distintos grupos armados en el país y en el mundo.

"Asumo una posición crítica frente a los procesos de paz que se han Ilevado a cabo en Colombia, teniendo en cuenta las posturas de las partes involucradas (pp. 38-39).

Complementariamente, el Ministerio de Educación Nacional (MEN) promulga la Cátedra por la Paz en mayo de 2015, en la que impone en todas las instituciones de educación básica y media la enseñanza de la cultura y la educación para la paz y el desarrollo sostenible. La variedad y heterogeneidad de temas que define esta normativa son: justicia y derechos humanos, uso sostenible de los derechos humanos, protección de las riquezas naturales y culturales, resolución pacífica de conflictos, prevención del acoso escolar, diversidad y pluralidad, participación política, memoria histórica, dilemas morales, historia de los acuerdos de paz y prevención de riesgos. Además se estipula que estos contenidos serán evaluados en las pruebas Saber 11 por parte del Icfes y que, en el futuro, el MEN podrá expedir lineamientos curriculares y demás orientaciones pedagógicas al respecto.

Como se nota, el tema referido al conflicto social y armado en estos documentos de la política pública viene aparejado a muchos asuntos neurálgicos para las sociedades contemporáneas, sin jerarquías claras y sin precisiones respecto a las condiciones institucionales para su implementación. Aspectos sociopolíticos, ambientales, culturales y de convivencia son ahora convocados en la escuela desde una mirada funcionalista que manifiesta la legendaria lógica de los gobiernos de turno de solucionar problemáticas sociales adicionando cátedras y sobreponiendo tareas y proyectos a la escuela ${ }^{1}$. De esta manera se corre el riesgo de crear reticencias en el cuerpo docente, bajo la idea que tramitar la violencia política

1 En Colombia las Ilamadas Cátedras se constituyen en un eufemismo que adiciona al currículo existente una serie interminable de proyectos pedagógicos supuestamente de obligatorio cumplimiento, a partir de necesidades políticas de ciertos sectores de la sociedad. Además de los proyectos transversales de educación sexual, educación ambiental y derechos humanos (Ley 115 de 1994); el estudio de la Constitución, el aprovechamiento del tiempo libre, la protección del medio ambiente, la educación para la justicia, la democracia, la paz y la educación sexual (Ley 1029 de 2006); de la prevención de la drogadicción (Ley 1098 de 2006); es obligatoria la Cátedra de estudios afrocolombianos (Decreto 1122 de 1998), la educación en normas de tránsito y seguridad vial (Ley 769 de 2002), la Cátedra de emprendimiento (Ley 1014 de 2006), la educación financiera y económica (MEN, 2014) y la más reciente Cátedra de la Paz (Decreto 1038 de 2015). 
en el aula será una más de las muchas actividades que se demandan a las instituciones educativas.

En suma, el boom de la memoria (Huyssen, 2002) sucede también en la escuela, de manera que libros de texto, nuevas asignaturas y cátedras, modificación en los planes de estudio, cursos de formación gradual y posgradual, cartillas y ayudas didácticas empiezan a invadir las escuelas con un tema tan sensible como novedoso y con consecuencias de todo orden. Es decir, a la vez que el tema se pone de moda, y exige que docentes y estudiantes tengan que dialogar al respecto, no queda claro si cuentan con las herramientas conceptuales y metodológicas para hacerlo. En esta dirección, para De Amézola (2011), cuando las políticas educativas de la memoria son impuestas a los maestros, se corre el riesgo de perpetuar la inercia de la cultura escolar, que suele adaptar los nuevos contenidos a las viejas prácticas. En efecto, como los imaginarios que circulan en la escuela provienen de múltiples escenarios sociales, muchas veces pesan menos los relatos de lo que la escuela enseña que lo que circula en los medios de comunicación, la calle o el sentido común respecto a las percepciones sobre el conflicto político y armado reciente. Aspecto especialmente importante para un contexto como el colombiano, en el que la proliferación de novelas centradas en la magnificación de victimarios y las aventuras que suponen las vidas del delito, han sido la constante.

Para Jelin y Lorenz (2004), si antes de las dictaduras existía una divergencia entre la historia oficial y las otras historias en la escuela, después dicha brecha se trasformó en un abismo. Para estos autores, las urgencias de la enseñanza del pasado reciente rompieron la antigua función de transmisión de la grandeza de la nación, ya que el compromiso con la tragedia que los profesores deben explicar coexiste ahora con la omisión y el silencio. Las alternativas son tan variadas como tantas las opciones éticas y políticas de los maestros.

Así las cosas, vale la pena preguntarse ¿qué ayudas pedagógicas es posible ofrecer a los docentes para el abordaje de la historia reciente?, ¿qué elementos de orden didáctico es pertinente tener en cuenta para trabajar con los estudiantes la memoria social?, y ¿qué tipo de recursos existen para hacer un abordaje pertinente de la violencia política en el aula? A estos interrogantes trata de dar respuesta lo que sigue del presente escrito.

\section{Estrategias didácticas sobre la violencia política}

Postular la iniciativa de pensar lo pedagógico a propósito de la historia reciente implica primeramente preguntarse el para qué de esta empresa. Aquí, conviene instalar de nuevo el sentido político del acto de educar, por cuanto no se trata de transmitir unos contenidos, sino de brindar las 
condiciones de posibilidad para que los escolares se asuman como sujetos capaces de modificar su realidad. Como diría Freire (2001):

\begin{abstract}
Por eso, para mí, uno de los contenidos esenciales de cualquier programa educativo, de sintaxis, de biología, de física, de matemáticas, de ciencias sociales, es lo que posibilita la discusión de la naturaleza cambiante tanto de la realidad natural como de la histórica y ve a los hombres y a las mujeres como seres que no solo son capaces de adaptarse al mundo, sino, sobre todo, de cambiarlo, seres curiosos, activos, hablantes, creadores (p. 106).
\end{abstract}

De manera que la aproximación a los conceptos del pasado reciente en la escuela se inspira en un deber ético y político, no tanto vigilante de la remembranza juiciosa de datos, hechos, lugares y número de fallecidos o de afectados, como sí del interés por incentivar en los estudiantes la indignación y el dolor ante la catástrofe acaecida, su comprensión y análisis en el marco de proyectos en disputa, y en tal sentido activar la capacidad de acción personal y colectiva para que tales acontecimientos no se repitan. En otras palabras, el objetivo es la contribución a la comprensión histórica y a la formación política escolar (Kriger, 2011), a partir del estudio de episodios que se prestan como pocos a tal fin. De lo contrario, la evocación de masacres y violaciones a los derechos humanos puede ahogarse en la inercia de un código disciplinar (Cuesta, 2014) que asume estos nuevos contenidos como responsabilidades pasajeras que deben ser retenidas mientras se obtiene una buena calificación y se llega a un nuevo tema.

Por otro lado, tratar los temas de la historia reciente interpela las predisposiciones morales frente a sucesos polémicos o de violencia política (Arias, 2015b; Ruiz, 2011), sobre los que mayoría de estudiantes pueden tener prejuicios adquiridos gracias a experiencias familiares, personales y sociales, por tanto, al trabajar estos aspectos en el aula, se debe contar con las condiciones biográficas y el contexto de los grupos en los que tales contenidos se cosechan.

Educar en la enseñanza del pasado reciente es promover la indagación crítica en los estudiantes, pero este objetivo no constituye una consigna vacía, sino que precisa ser detallado, Ilenado de contenido, cargado de ética, por ello metodológicamente la propuesta se acoge al planteamiento de Bermúdez (2015), para quien el pensamiento crítico se puede traducir en cuatro ejercicios: planteamiento de problemas, escepticismo reflexivo, multi-perspectividad y pensamiento sistémico. Estos no deben ser asumidos como pasos de un proceso, sino más bien como ejes que, en la medida en que son abordados y explicitados, ofrecen un terreno propicio para la apropiación de discursos ligados a la historia próxima, o, en palabras de la autora, para procesar datos y sortear desafíos intelectuales y sociales en situaciones de conflicto y controversia. 
Para Bermúdez (2015), plantear problemas quiere decir incentivar la capacidad de formular preguntas en medio de supuestos y verdades aparentemente evidentes. Al respecto afirma: "esta herramienta es fundamental en la indagación crítica porque con ella el conocimiento se torna significativo y relevante. Las preguntas críticas conectan el conocimiento y la práctica a través de ciclos de praxis: la experiencia práctica interroga al conocimiento existente, y cada nueva reflexión arroja nueva luz sobre la práctica" (p. 106). Problematizar es también cuestionar ciertas afirmaciones basadas en el poder de la autoridad o de la tradición, sus incoherencias y su descuido respecto a sus implicaciones en lo moral y lo humano. Es preguntarse por las lógicas de poder y saber que vehiculan determinados discursos hegemónicos. El radar es la metáfora que usa la autora para graficar esta capacidad.

Al decir de Siede (2010) la función de la pregunta no consiste solo en abrir sino en orientar, en desafiar lo que se puede pensar a partir de lo que se sabe, a la vez "abre un enigma para resolver, su enunciado postula el espacio dentro del cual será posible construir la respuesta" (pp. 275-276).

Por su parte, el escepticismo reflexivo consiste en el escrutinio de los argumentos y procedimientos del pensamiento, el examen de los supuestos y el develamiento de las distorsiones, es decir, hay que revisar la coherencia de las argumentaciones, su soporte en evidencias, los intereses de las premisas no objetadas y los fundamentos ideológicos presentes y que se legitiman. El escepticismo reflexivo alerta frente a la lectura neutra de la realidad y la manipulación. Su ejecución requiere juicio, detalle, tiempo y dedicación. Un bisturí es el objeto con el cual podría compararse, según Bermúdez (2015), esta habilidad por enseñar en la escuela.

El siguiente postulado, la multiperspectividad, se utiliza para "identificar, reconstruir y coordinar distintas perspectivas que son relevantes para comprender un problema" (p. 108). Aquí es importante el reconocimiento de las versiones puestas en juego en las afirmaciones, una especie de imaginación empática que descentra el propio foco, "ponerse en los zapatos del otro" suele decirse. La multiperspectividad también significa poner en juego nuevas miradas frente al fenómeno estudiado o, mejor dicho, integrar diferentes perspectivas en relatos más abarcantes para asegurar su comprensión, en la línea del pensamiento complejo, lo mismo que propender por el reconocimiento de los relatos en su contexto de enunciación, contra la universalización. Esta herramienta se preocupa por propiciar otras maneras de pensar sobre el asunto en cuestión. Un director de orquesta, según la autora, podría ser un símbolo que contribuye a entender qué es una multiperspectiva.

Por último, el pensamiento sistémico es la cuarta estrategia que propone Bermúdez (2015) para desarrollar el pensamiento crítico; este consiste 
en la deconstrucción y reconstrucción de los procesos más amplios en los que los sujetos actúan. Para la autora, "mediante el mapeo de elementos, relaciones y transformaciones, esta herramienta construye relatos y explicaciones críticas que muestran cómo los fenómenos interpersonales, sociales e históricos son multidimensionales, interdependientes, dinámicos, socialmente construidos y basados en estructuras sociales subyacentes" (p. 110). Esta disposición se da cuando se va de lo macro a lo micro y viceversa, en una relación abierta de análisis, cuando se deshacen las variables que componen un fenómeno y se vuelven a juntar, cuando se rastrean las causas en el tiempo, y cuando se profundiza en las estructuras sociales, aparentemente ocultas, que contribuyen a explicar la realidad. La autora sugiere el lente de una cámara como metáfora del pensamiento sistémiCo, pues el cerrar y abrir el foco permite hallar analogías en el espacio y el tiempo sin dejar perder las especificidades de lo estudiado. Además, esta habilidad favorece el sentido de agencia, porque al "rastrear procesos históricos de cambio, esta herramienta desnaturaliza los fenómenos sociales, mostrando que no son estados naturales e inmutables, sino realidades construidas socialmente sobre las que podemos actuar" (p. 111).

Cualquier recurso didáctico en función de la comprensión del pasado reciente puede estructurarse en torno a los anteriores ejes, en la medida en que ellos abren un abanico de posibilidades en el momento de querer profundizar sobre variables y aspectos por tener en cuenta con respecto al periodo histórico que se va a estudiar. Hablar en la escuela sobre el Bogotazo, el Frente Nacional, la violencia guerrillera, el narcotráfico o el terrorismo estatal, por ejemplo, de acuerdo a esta propuesta, propenderá hacia el pensamiento crítico en la medida en que con cada uno de ellos se puedan plantear problemas, se ejercite el escepticismo reflexivo, cada fenómeno se despliegue en múltiples perspectivas para ser comprendido $y$, finalmente, se rearme la situación desde un horizonte sistémico que no solo abarque la comprensión del mismo, sino que lo vincule a realidades estructurales, a la vez que provoque, en los estudiantes, capacidad de agencia. Lógicamente el nivel de profundidad y el alcance de cada componente dependerá de las edades, los niveles y la cultura escolar (Viñao, 2002) en los que estos temas se encarnen.

Existe una amplia variedad de recursos didácticos que pueden ser usados para abordar los temas de la formación de la subjetividad política y la historia reciente en el aula, que van desde la historia oral (Támara y Velasco, 2006), los proyectos pedagógicos de aula (Vasco y otros, 1999), las salidas a lugares emblemáticos y museos (De Amézola, 1999), el trabajo con prensa (Vega, 2011), el abordaje desde la fotografía y la imagen (Arias y Riveros, 2014; Augustowky, 2012; Caldarola, 2013), la literatura (Ruiz y Prada, 2012) y el cine (Paladino, 2004; Serra, 2004). En lo que sigue se profundizará en las ayudas audiovisuales (películas y documentales) 
referidas al conflicto y a la violencia política en Colombia, dada su variedad, su cercanía a las sensibilidades juveniles y la facilidad de acceso a la mayoría del material existente por medio de la web.

\section{Formatos audiovisuales como ayuda didáctica para la enseñanza de la historia reciente}

La imagen, al representar el lenguaje privilegiado del mundo contemporáneo, impone también una pedagogía de la imagen (Dussel y Gutiérrez, 2006), que debe ofrecer posibilidades para que los estudiantes analicen la carga de lo presentado, lo pongan en relación con otras imágenes, relatos, textos y miradas sobre la realidad. La producción audiovisual, que es una modalidad de trabajo de la imagen en movimiento, al ser una construcción humana, no puede considerarse como un reflejo de la realidad o como una copia que retrotrae la versión fidedigna de lo que ha sucedido.

Para Martínez y Orozco (2012), el cine, junto con otras producciones artísticas, invitan a mirar por las fisuras de lo evidente, no porque muestren lo que sucede, "sino porque cobijan excesos, fragmentos, silencios, una especie de estar afuera de nosotros mismos" (p. 51). Agregan estos autores que lo audiovisual "lejos del lenguaje que satura, que intenta explicarlo todo, nos abren un resquicio, sugieren nuevas visibilidades para viejos problemas" (p. 51). Por eso el cine ayuda a pensar, a problematizar, a interrogar, a "historizar aquello que aparece como verdadero y lograr develar que tiene relaciones con el poder, aún más, es el poder el que lo enuncia como verdad" (p. 54).

Acudir al uso de material audiovisual sobre el pasado reciente en el aula, en el marco de las anteriores afirmaciones, no es entonces pretender presentar la verdad de lo sucedido. Es, al decir de Larrosa (2007), educar la mirada, o sea, ofrecer la posibilidad para luchar por imágenes en movimiento que conecten con el mundo, con la vida, lo que convoca evitar

imágenes que no nos dejan pensar, o que no nos hacen pensar, que no se dirigen a nosotros como seres pensantes, o pensativos. Y son las imágenes, por último, que no pueden integrarse en la vida, que no establecen ninguna relación con la vida, con la nuestra y la de los otros, que nos desconectan de nuestra vida, de nosotros mismos, y nos desconectan también de los otros, de la vida de los otros (p. 11).

En la actualidad, el texto audiovisual sobre pasados recientes se constituye en una poderosa expresión cultural, cuya carga política puede reforzar o poner en cuestión formas sociales y configuraciones subjetivas presentes; aspecto especialmente fuerte cuando este material expuesto hace alusión a conflictos sociopolíticos de reciente ocurrencia, cuyo 
impacto aún retumba en el ser de sus protagonistas o de sus herederos. Valga afirmar que en algunos países, el tema de la represión y las dictaduras entró a las aulas precisamente de la mano de la cultura audiovisual (González, 2014).

El cine y el documental cuentan con amplia difusión en el mundo contemporáneo gracias a la masificación de la televisión, las salas de cine y la divulgación de imágenes por internet. Por otra parte, estos recursos comunicativos tienen la enorme ventaja de hacerse sobre una estructura narrativa que facilita la captura del espectador gracias a su inmersión en la historia, su vínculo con la trama, sus elipsis y su realismo deslumbrante. Pero estos elementos que garantizan la captura y la seducción del espectador, precisamente delinean su límite y si riesgo. Dicen Amieva, Arreseygor, Finkel y Salvatori (s. f.) que "la ilusión de realidad que genera la imagen en movimiento es tan potente que olvidamos que estamos frente a una representación de la realidad y creemos fácilmente que lo que estamos viendo es la realidad de esa época particular sin ningún tipo de mediación" (p. 8). Para el tema de la violencia política en la escuela, su exposición en dispositivos audiovisuales, corre el peligro de presentarse como el reflejo verdadero o auténtico de lo ocurrido, por ello se requiere de la mediación pedagógica, que problematiza lo observado a partir del pensamiento crítico, cuyas características se anotaron en el apartado anterior.

En honor al sentido de la creación artística que configura el cine ${ }^{2}$, cuyo propósito trasciende de lejos los reducidos usos que se le puedan dar en la escuela, se asume que este formato ayuda a pensar, que su estructura puede ser estirada para servir a ciertos objetivos pedagógicos, que su abordaje puede ayudar a educar la mirada (Larrosa, 2006) sobre temas controversiales respecto a pasados polémicos en la historia de la nación. No se trata entonces de moralizar, ni de dar lecciones, ni de anticipar conclusiones o verdades. En esta línea, para Larrosa:

a veces, el cine salva las imágenes de nuestra voracidad, de nuestra voracidad estética, ideológica, política, de nuestra voracidad moral también, y las devuelve al silencio. A veces, el cine no representa nada, no analiza nada, no interpreta nada, sino que deja que el ojo se pose literalmente sobre la superficie de la cosas. A veces, el cine, como arte de lo visible, simplemente, nos enseña a mirar (2006, p. 132).

2 Según Larrosa (2006), el cine es una estrategia de producción discursiva centrada en la imagen en movimiento, por tanto irreductible a palabras a las ideas, "y con esas imágenes móviles a las que se incorporan palabras y sonidos, el cine, a veces, solo a veces, cuenta una historia. Digamos que el cine es el arte de lo visible que, gracias al movimiento, se habría dado la capacidad del relato. Y también, sin duda, otras muchas capacidades, muchas de ellas aún desconocidas. Nadie ha dicho que el cine sea solo un artefacto de contar historias" (p. 114). 
Para este autor, las películas representan la alteridad, que exigen una especial apertura y una atención despojada de intenciones. Piden tiempo, receptividad, silencio, pues "nos hacen sentir la entraña del mundo, su latido invisible, las que apuntan hacia lo que no se puede ver, las que señalan hacia lo que no se puede decir" (Larrosa, 2006, p. 133).

Por eso, no se trata de provocar análisis de cómo hacer cine o de cómo convertir a los estudiantes en críticos de arte, sino de hacer uso de este, con propósitos didácticos y pedagógicos, junto con otros materiales didácticos como fotografías, textos o grabaciones de audio. Es un aprovechamiento que es consciente de sus limitaciones.

El uso de los recursos artísticos y audiovisuales es de vieja data en la escuela (Augustowsky, 2012). Cuando se habla de violencia política e historia reciente, es numeroso el material de que se puede disponer en la escuela. Para Amieva et ál. (s. f.) las películas pueden ayudar a comprender sucesos históricos ya que pueden sacar a la luz aspectos no visibles en documentos escritos, por ello conviene acotar el sentido sobre las posibilidades del mismo, para lo cual especifica varios usos, a saber:

El cine como fuente de la historia, aquí se usa como base de información, ya que recopila miradas sobre un acontecimiento, tales como las grabaciones en vivo, los documentales o los noticieros; también incluye películas que permiten observar el trasfondo y la época en que fueron creadas. Según los autores, "aquí no es tan importante considerar cuán útiles nos pueden resultar las imágenes para ilustrar el hecho, sino que logran, a veces a pesar suyo, iluminar la sociedad que las produjo" (pp. 2-3). Por otra parte está el cine como relato histórico, en este caso importa la articulación de las imágenes, el texto y la banda sonora, que transmiten un relato, que presentan una narración que recrea un momento del pasado; en este punto el cine alcanza mayores dimensiones que el texto escrito. Seguidamente, Amieva et ál. (s. f.) mencionan el cine como agente de la historia, para aludir a la potencia del relato audiovisual para intervenir e incidir en la sociedad que lo genera. El ejemplo más claro es el cine de propaganda política "en los que las películas son generadas pensando en el impacto deseado y con una clara intención de provocar una reacción determinada" (p. 3). Aquí el cine es utilizado explícitamente como herramienta política en pro de un proyecto determinado. Finalmente, está el cine como vector de memoria, cercano a la modalidad anterior, constituido por películas que simbolizan la construcción de la memoria frente a un hecho, al punto de reemplazar los recuerdos que muchas personas tienen sobre un acontecimiento y reinscribirlos en la matriz de las imágenes que ofrece; películas que "terminaron por enseñarles a las nuevas generaciones las formas posibles, muchas veces predominantes, de pensar un hecho" (p. 3).

Dependiendo de la época en que fue filmado, o de las pretensiones del director, es clave identificar a qué tipo de cine se accede, pues ello 
determina sus alcances y las posibilidades de reflexión que puede generar en el aula.

A continuación se presenta una lista de algunas películas disponibles en el mercado sobre el tema de la violencia política en Colombia y su historia reciente, muchas de ellas con descarga gratuita por la web.

\begin{tabular}{|c|c|}
\hline Película / Año & Director \\
\hline El río de las tumbas (1964) & Julio Luzardo \\
\hline La tormenta (1979) & Fernando Vallejo \\
\hline Crónica roja (1979) & Fernando Vallejo \\
\hline Canaguaro (1981) & Dunav Kuzmanich \\
\hline Cóndores no entierran todos los días (1983) & Francisco Norden \\
\hline Carne de tu carne (1983) & Carlos Mayolo \\
\hline Tiempo de morir (1985) & Jorge Alí Triana \\
\hline El potro chusmero (1985) & Luis Alfredo Sánchez \\
\hline El hombre de acero (1985) & Carlos Duplat \\
\hline Técnicas de duelo (1988) & Sergio Cabrera \\
\hline Confesión a Laura (1991) & Jaime Osorio \\
\hline Edipo alcalde (1996) & Jorge Alí Triana \\
\hline Golpe de estadio (1998) & Sergio Cabrera \\
\hline La virgen de los sicarios (1999) & Barbet Schroeder \\
\hline La toma de la embajada (1999) & Ciro Durán \\
\hline La primera noche (2003) & Luis Alberto Restrepo \\
\hline La sombra del caminante (2004) & Ciro Guerra \\
\hline PVC-1 (2007) & Spiros Stathoulopoulos \\
\hline Los actores del conflicto (2008) & Lisandro Duque \\
\hline La pasión de Gabriel (2009) & Luis Alberto Restrepo \\
\hline Retratos en un mar de mentiras (2010) & Carlos Gaviria \\
\hline Los colores de la montaña (2010) & Carlos César Arbeláez \\
\hline Postales colombianas (2011) & Ricardo Coral Dorado \\
\hline La toma (2011) & Angus Gibson \\
\hline Silencio en el Paraíso (2011) & Colbert García \\
\hline Pequeñas voces (2011) & $\begin{array}{l}\text { Jairo Eduardo Carrillo, Óscar } \\
\text { Andrade }\end{array}$ \\
\hline El páramo (2012) & Jaime Osorio \\
\hline El silencio del río (2012) & Carlos Triviño \\
\hline Estrella del sur (2013) & Gabriel González \\
\hline Roa (2013) & Andrés Baiz \\
\hline Antes del fuego (2014) & Laura Mora \\
\hline
\end{tabular}




\begin{tabular}{|l|l|}
\hline \multicolumn{1}{|c|}{ Película / Año } & \multicolumn{1}{c|}{ Director } \\
\hline Manos sucias (2014) & Josef Kubota Wladyka \\
\hline La Siempreviva (2015) & Klych López \\
\hline Carta a una sombra (2015) & Daniela Abad \\
\hline Sargento Matacho (2015) & William González \\
\hline Alias María (2O15) & José Luis Rugeles \\
\hline Un asunto de tierras (2015) & Patria Ayala \\
\hline
\end{tabular}

Como todo texto, los materiales fílmicos deben ser tratados como documentos narrativos, por tanto con intencionalidades y contextos de enunciación, así, al trabajar este tipo de documentos visuales es importante tener en cuenta que ellos constituyen excusas para el abordaje de temáticas históricas relacionados con el conflicto y no versiones legítimas sobre lo sucedido. En este sentido, conviene tener en cuenta la reflexión de Lorenz (2003) a propósito del abuso de la película La noche de los lápices en los espacios escolares argentinos. La presentación de este video coincide en la Argentina con el día 16 de septiembre, día nacional de la juventud en conmemoración de los jóvenes desaparecidos durante la dictadura. Si bien logra posicionar el tema de los derechos humanos en la población escolar, al ser un recurso didáctico legítimo, según el autor, presenta la dificultad de no ilustrar convenientemente el contexto en el que sucedieron los hechos, además de provocar el temor en los jóvenes hoy ajenos a esa situación ante imágenes de tortura explícita, desalentar así la participación política, y de incitar la solidaridad con el dolor de unos colegas que padecieron vejámenes hace varios años pero sin la posibilidad de interpelar el presente. Para el autor,

relatando experiencias intransferibles y que realzan por eso mismo las virtudes de los protagonistas de la tragedia, sin un contexto histórico que al mismo tiempo las torne comprensibles, el emblema que conforman adquiere ribetes de "ajenidad" que alejan a los alumnos de sentir esas historias como parte de su propio pasado (Lorenz, 2003, p. 125).

De acuerdo a las anteriores ideas, el material fílmico debe estar supeditado al para qué de la pregunta didáctica, de manera que, en lo posible, sirva para generar problematizaciones propias del pensamiento crítico, tal como se indicó con Bermúdez (2015) en el anterior apartado. Al decir de Dussel y Gutiérrez (2006) "frente a aquello que nos enmudece, nos supera, nos conmueve y nos afecta, probablemente la tarea de la educación sea ofrecer palabras" (p. 11). Por ello no se trata solo de reconstruir las narrativas expuestas en la película, aunque haya que pasar por ello, y recorrer las tramas, los diálogos más impactantes y los escenarios que 
transmiten intencionalidades, también será necesario preguntarse por el presente, es decir, por las situaciones similares se hayan vivido en el hoy, así como por las experiencias personales experimentadas por los docentes y los estudiantes a propósito de lo tratado.

En algunos casos se trata de permitir la entrada de una realidad posiblemente ajena a la escuela, por una puerta no convencional. Se trata de que en la experiencia escolar,

abrir las puertas al cine bien podría ser un modo de que lógicas, voces e imágenes extrañas, extranjeras, la visiten, suspendan sus certezas por un momento y hagan otra cosa de ella. Si el ojo de la pantalla es capaz de alterar el régimen de lo subjetivo [...], quizá debamos otorgarle algún crédito para que habite e interrogue la escena escolar (Serra, 2006, p. 153).

El Centro Nacional de Memoria Histórica ${ }^{3}$ cuenta con una plataforma virtual con muchas ayudas audiovisuales que pueden apoyar el trabajo en el aula. Existen documentales sobre varios temas, lo mismo que audios, relatos gráficos, entrevistas y recursos multimedia, entre otros.

Por su parte, el formato documental, que a diferencia del cine tiene la pretensión de captar los matices de la realidad sin la carga ficcional, también puede constituirse en un poderoso recurso para abordar el tema de la violencia política en el aula. La mayoría de ellos también se pueden conseguir en forma gratuita en la web. A continuación se ofrece una lista de algunos documentales referidos al tema del conflicto y la violencia política en Colombia.

\begin{tabular}{|l|l|}
\hline \multicolumn{1}{|c|}{ Documental / Año } & \multicolumn{1}{c|}{ Director(a) } \\
\hline Contravía. Los niños en el conflicto armado (2003) $^{-}$ & Hollman Morris \\
\hline Mujeres no contadas (2005) & Ana Cristina Monroy \\
\hline Hasta la última piedra (2006) & Juan José Lozano \\
\hline Contravía. Confesiones de un exparamilitar (2007) & Hollman Morris \\
\hline El Bogotazo, la historia de una ilusión (2008) & $\begin{array}{l}\text { The History Channel, Canal Caracol } \\
\text { y Mazdoc Documentaries }\end{array}$ \\
\hline
\end{tabular}

Continúa

3 Es un organismo público de carácter nacional que tiene como fin recuperar y reunir todo lo relacionado con las violaciones a los derechos humanos en el marco del conflicto armado colombiano. Entre sus objetivos estratégicos están: comprensión social del conflicto armado, esfera pública de la memoria, condiciones para la construcción de la paz, legado testimonial y documental, Museo Nacional de la Memoria, archivo de derechos humanos y memoria histórica (www.centrodememoriahistorica.gov.co).

4 Contravía es un programa que ha producido más de 250 documentales para la televisión sobre memoria, derechos humanos y violencia política en Colombia, emitido desde el 2003, dirigido por Hollman Morris con la financiación del Programa Andino para la Democracia y los Derechos Humanos -País Colombia- y auspiciado por la Unión Europea. 


\begin{tabular}{|c|c|}
\hline Documental / Año & Director(a) \\
\hline $\begin{array}{l}\text { El baile rojo. La historia del genocidio contra la Unión } \\
\text { Patriótica (2007) }\end{array}$ & Yesid Campos \\
\hline Gaitán, el Bogotazo. Historia de una ilusión (2008) & Mauricio Acosta \\
\hline Invisibles (2008) & Javier Bardem \\
\hline Falsos positivos (2009) & Simone Bruno, Dado Carillo \\
\hline La pobreza: un "crimen" que se paga con la muerte (2010) & Felipe Zuleta \\
\hline Bojayá: la guerra sin límites $(2010)^{5}$ & $\begin{array}{l}\text { Centro Nacional de } \\
\text { Memoria Histórica }\end{array}$ \\
\hline Robatierra (2011) & Margarita Martínez, Miguel Salazar \\
\hline Impunity (2011) & Hollman Morris, Juan Lozano \\
\hline El Palacio de Justicia (2011) & Mauricio Acosta \\
\hline Cuando sea grande (2011) & Lina Arias \\
\hline Especiales Pirry. Tumaco (2011) & Guillermo Prieto \\
\hline Cartas a la memoria (2012) & Jonhatan Acevedo, Nicolás Mejía \\
\hline Mujeres tras las huellas de la memoria (2012) & María Libertad Márquez \\
\hline Oslo (2012) & Juan Soto \\
\hline De panes, surcos y libertad (2013) & Ángela Rubiano, Paola Figueroa \\
\hline Apuntando al corazón (2013) & Claudia Gordillo, Bruno Federico \\
\hline No hubo tiempo para la tristeza (2013) & Centro de Memoria Histórica \\
\hline Gotas que agrietan la roca (2013) & Antonio Girón \\
\hline Fábulas de tierra y memoria (2014) & Centro de Memoria Histórica \\
\hline Sabogal $(2015)^{6}$ & Juan José Lozano, Sergio Mejía \\
\hline Las niñas de la guerra $(2015)^{7}$ & Cesar Espinosa, Yoleiza Toro \\
\hline Pueblo sin tierra & $\begin{array}{l}\text { Centro Nacional de } \\
\text { Memoria Histórica }\end{array}$ \\
\hline
\end{tabular}

La fuerza del documental radica en la captura de imágenes con personas comunes y tragedias reales cuya edición busca generar mayor impacto en el espectador. La tentación de realismo tiene más peso en este formato, por tanto es más exigente su mediación pedagógica. El sensacionalismo con el que la mayoría de noticieros en el país manejan el

5 El Centro Nacional de Memoria Histórica tiene en su plataforma (www.centrodememoriahistorica.gov.co) un espacio de ayudas audiovisuales que permite descargar varios documentales y videos sobre diferentes temáticas vinculadas a la memoria así como a la reivindicación, expresión y violación a los derechos humanos en diferentes zonas del país.

6 Serie animada en 3D de 13 capítulos producida por la televisión pública Canal Capital, que reconstruye la historia de un abogado defensor de derechos humanos entre 1999 y 2009.

7 Serie animada producida por el Ministerio de las TIC sobre el reclutamiento de niños en el conflicto armado. 
tema del conflicto armado,con un tratamiento episódico, superficial y fragmentado, contribuye a la creación de un sentido común que banaliza la tragedia y a fuerza de repetición descontextualizada satura frente a los temas de la violencia. De aquí la importancia de ambientar adecuadamente los documentales sobre la violencia política, de garantizar climas sociales propicios para dejarse interrogar e impedir a toda costa que los ejercicios propuestos contribuyan a la insensibilidad, la indiferencia y el acostumbramiento que la naturalización de la barbarie ocasiona.

Desde lo pedagógico, no es posible establecer rutas fijas para trabajar en el aula los temas de la enseñanza reciente desde los registros audiovisuales; existen diversas propuestas educativas para tratarlos. Caldarola (2013) sugiere frente a estos contenidos audiovisuales el abordaje por pequeños grupos a partir de las siguientes consignas:

» [que los estudiantes] reconozcan el contexto del acontecimiento, analicen las acciones de los protagonistas, los niveles de responsabilidad y sus consecuencias;

» manifiesten por escrito sus argumentos;

» sean invitados a debatir con fundamento sobre las posturas que surjan;

» elaboren conclusiones que busquen una incidencia en su propia vida, es decir, encuentren una manera de continuar conviviendo en el aula después de hacer públicas las situaciones personales y familiares (p. 23).

Por su parte, Amieva et ál. (s. f.) recomiendan desarrollar dos planos de discusión: lo que la película cuenta (historia principal y secundaria, pretensiones del relato, características y valores de los personajes, nudo, trama y conflictos presentes) y los recursos cinematográficos que se utilizan para narrar (planos, ángulos, tomas, énfasis en las tomas, luz, colores, sonido, montaje, etc.).

A su vez, González (2014) sugiere retomar el asunto en tres niveles: el conocimiento, la emoción y la acción. Ello consiste en conocer por qué sucedieron las cosas e identificar responsables, sentir conmoción ante el dolor de los otros y, finalmente, estar dispuestos a hacer algo para solucionar la situación presentada. Para la autora, formulando algunas preguntas como "¿qué muestra y a quién muestra?, ¿qué me produce esa imagen?, ¿qué puedo hacer? [...] podríamos animarnos a mirar, saber, interpretar, preguntar y enfrentar un pasado difícil y doloroso que continúa presente" (p. 166).

En la última parte de este escrito se hace una propuesta de tramitación didáctica de un material audiovisual: En un primer momento, antes de la presentación del audiovisual, se requiere abrir la temática con un conjunto de preguntas respecto a la temática que trata. En un segundo momento conviene hacer una contextualización del audiovisual, su eje 
central, su dirección y la trayectoria de este. Vale la pena dirigir la mirada hacia momentos clave, a diálogos importantes o escenas clave.

Al presentar el video, tercer momento, recordar que se trata de un material didáctico, por tanto es procedente hacer pausas, recortes o rebobinados para hacer énfasis o captar imágenes o diálogos trascendentales. Aquí se pueden asignar a los estudiantes distintos roles en su mirada, es decir, sugerir que algunas personas detallen en ciertos personajes, en ciertos escenarios o en ciertas narraciones, ello permite sacar mayor provecho a lo presentado, al punto que, si se requiere, puede volverse a presentar el documento fílmico para repasar detalles.

Extraer con los estudiantes la lista de palabras, temas o referencias que no se entienden o cuya aclaración es necesaria para seguir el hilo argumental del audiovisual. Por ejemplo pueden existir referencias a la violencia bipartidista, o mencionar a "los pájaros", o escuchar alusiones a la época de la violencia que precisan ser aclaradas conceptualmente.

Luego de la presentación del audiovisual, cuarto momento, se pueden retomar los criterios del pensamiento crítico expuestos por Bermúdez (2015). Respecto al planteamiento de problemas, formular preguntas como ¿Cuáles son las pretensiones del autor del documental?, ¿qué intereses hay en pugna?, ¿qué versiones oficiales circulan sobre el tema?, ¿por qué ciertas voces han sido acalladas? Sobre el escepticismo reflexivo, dudar de los relatos de la historia hegemónica, presente en los medios de comunicación o en los libros de texto imperantes, analizar en detalle algunos de ellos y evidenciar las lógicas que transmiten. En la misma línea de pensamiento crítico, sobre la multiperspectiva, cotejar otras versiones sobre el tema de estudio, explorar voces no conocidas e indagar en relatos de las víctimas. Finalmente respecto al pensamiento sistémico, se podrían sugerir lecturas que articulen el acontecimiento a procesos políticos mayores, como por ejemplo el desmonte de derechos sociales y políticos adquiridos, el quiebre del pensamiento opositor o la expansión del proyecto paramilitar o del capital financiero, dependiendo el caso. Sobre este último punto también se puede profundizar sobre el tipo de subjetividades que producen hechos traumáticos, específicamente situaciones como la desconfianza, el miedo, la indiferencia y el conformismo ante el dolor ajeno.

Hasta aquí se ha intentado resaltar la importancia de tramitar aspectos del conflicto político y armado en el aula, no sin antes repasar algunas conceptualizaciones referidas a la historia reciente y a la memoria como recursos devenidos de sectores sociales para disputar sentidos y versiones proclives de ser trabajadas en la escuela. En este escenario se subrayaron, por varias razones, los recursos audiovisuales como poderosas herramientas cuyo uso podría ampliar la comprensión del pasado reciente, máxime en un contexto como el colombiano, con un largo periodo de guerra pero con muy cortas referencias sobre su abordaje en la escuela. 
Retomando a Matengazza (2006), con la historia de los jóvenes de Auschwitz con la que inició el presente artículo, hay que decir que las representaciones sobre el pasado cercano no dependen solamente de lo que la escuela hace, aunque, en parte, depende en algo de lo que deja de hacer. Es decir, desde las aulas no se puede renunciar a intentar ayudar para que la barbarie no se repita, o en nuestro caso colombiano, que no se siga dando. 


\section{Referencias bibliográficas}

Adorno, T. (1998). Educación para la emancipación. Madrid: Morata.

Amieva, A.; Arreseygor, G.; Finkel, R. y Salvatori S. (s. f.). Cine y memoria, 1. a parte. Dossier Educación y memoria. Recuperado de: http://www. elortiba.org/pdf/10.pdf.

Anderson, B. (1993). Comunidades imaginadas: reflexiones sobre el origen y la difusión del nacionalismo. Buenos Aires: Fondo de Cultura Económica.

Arias, D. (2015a). Identidad nacional y escuela en Colombia. ¿Un cruce necesario? En B. García (ed.), Escuela y educación superior: temas para la reflexión (pp. 43-60). Bogotá: Universidad Distrital Francisco José de Caldas.

Arias, D. (2015b). La enseñanza de la historia reciente y la formación moral. Dilemas de un vínculo imprescindible. Folios, 42, 29-41.

Arias, D. y Riveros, N. (2014). Educación para la convivencia y la ciudadanía. Jóvenes para el empoderamiento y la transformación social. Ciclo 5. Bogotá: Secretaría de Educación del Distrito, Fe y Alegría.

Augustowsky, G. (2012). El arte en la enseñanza. Buenos Aires: Paidós.

Bermúdez, Á. (2015). Four tools for critical inquiry in History, Social Studies, and Civic Education. Revista de Estudios Sociales, 52, 102-118.

Caldarola, G. (2013). Herramientas para enseñar historia reciente. Buenos Aires: Aique.

Caldo, P. (2014). Transmitir el pasado reciente... Una reflexión sobre los actos del día de la memoria por la verdad y la justicia en las escuelas medias de Rosario. Revista de la Escuela de Ciencias de la Educación, 5, 137-153.

Calveiro, P. (2006). Usos políticos de la memoria. En G. Gaetano (comp.). Sujetos sociales y nuevas formas de protesta en la historia reciente de América Latina (pp. 359-382). Buenos Aires: Clacso.

Carretero, M. y Kriger, M (2004). ¿Forjar patriotas o educar cosmopolitas? El pasado y el presente de la historia escolar en un mundo global. En M. Carretero y J. Voss (comps.), Aprender y pensar la historia (pp. 71 98). Buenos Aires: Amorrortu.

Cuesta, R. (2014). Genealogía y cambio conceptual. Educación, historia y memoria. Archivos Analíticos de Políticas Educativas, 23, 1-25.

De Amézola, G. (1999). Problemas y dilemas en la enseñanza de la historia reciente. Revista Entrepasados, 17, 137-162.

De Amézola, G. (2011). La última dictadura militar en la escuela argentina: entre la historia reciente y la memoria colectiva. Revista de Teoría y Didáctica de las Ciencias Sociales, 17, 29-56.

Del Pozo, M. (2000). Currículum e identidad nacional. Regeneracionismos, nacionalismosyescuelapública(1890-1939). Madrid:BibliotecaNueva. 
Dussel, I. y Gutiérrez, D. (2006). Educar la mirada. Políticas y pedagogías de la imagen. Buenos Aires: Manantial.

Erice, F. (2008). Memoria histórica y deber de memoria: las dimensiones mundanas de un debate académico. Revista Interdisciplinar Entelequia, 7, 77-96.

Forges, J. F. (2006). Educar contra Auschwitz. Historia y memoria. Barcelona: Anthropos.

Freire, P. (2001). Pedagogía de la indignación. Madrid: Morata.

González, M. (2014). La historia reciente en la escuela. Saberes y prácticas docentes en torno a la última dictadura. Los Polvorines: Universidad Nacional General Sarmiento.

Herrera, M.; Pinilla, A. y Suaza, L. (2003). La identidad nacional en los textos escolares de ciencias sociales. Bogotá: Universidad Pedagógica Nacional.

Herrera, M. y Vélez, G. (2014). Formación política en el tiempo presente: ecologías violentas y pedagogía de la memoria. Nómadas, 41, 149-165.

Hobsbawm, E. y Ranger, T. (1983). La invención de la tradición. Barcelona: Crítica.

Jaramillo, J. (2011). El giro hacia el pasado. Reflexiones sobre su naturaleza e impactos. Folios, 33, 65-80.

Jelin, E. (2005). Exclusión, memorias y luchas políticas. En D. Mato (comp.), Cultura, política y sociedad Perspectivas latinoamericanas (pp. 219-239). Buenos Aires: Clacso.

Jelin, E. y Lorenz, F. (2004). Educación y memoria: entre el pasado, el deber y la posibilidad. En E. Jelin y F. Lorenz (comps.), Educación y memoria. La escuela elabora el pasado (pp. 1-10). Madrid: Siglo xxı.

Kriger, M. (2011). La enseñanza de la historia reciente como herramienta clave de la educación política. Persona y Sociedad, 3, 29-52.

Larrosa, J. (2006). Niños atravesando el paisaje. Notas sobre cine e infancia. En I. Dussel y D. Gutiérrez. Educar la mirada. Políticas y pedagogías de la imagen (pp. 113-134). Buenos Aires: Manantial.

Larrosa, J. (2007). Las imágenes de la vida y la vida de las imágenes: tres notas sobre el cine y la educación de la mirada. Educação e realidade, $32,7-22$.

Lechner, N. (2002). Las sombras del mañana. La dimensión subjetiva de la política. Santiago de Chile: Lom.

Lomas, C. (2011). Tiempo de olvidos, tiempo de memoria. En C. Lomas (coord.). Lecciones contra el olvido. Memoria de la educación y educación de la memoria (pp. 9-20). Barcelona: Octaedro.

Lorenz, F. (2003). "Tomála vos, dámela a mí". La Noche de los Lápices: el deber de recordar y las escuelas. En E. Jelin y F. Lorenz (comps.), Educación y memoria. La escuela elabora el pasado (pp. 95-130). Madrid-Buenos Aires: Siglo XxI. 
Martínez, A. y Orozco, J. (2012). Cine y educación. Campo de visión, movimiento, velocidad y poder. Revista Colombiana de Educación, 63, 49-66.

Ministerio de Educación Nacional. (2004a). Formar para la ciudadanía jsí es posible! Lo que necesitamos saber y saber hacer. Bogotá: Autor.

Ministerio de Educación Nacional. (2004b). Formar en ciencias jel desafío! Lo que necesitamos saber y saber hacer. Bogotá: Autor.

Ministerio de Educación Nacional. (2014). Mi plan, mi vida y mi futuro. Orientaciones pedagógicas para la educación económica y financiera. Bogotá: Autor.

Paladino, D. (2004). Qué hacemos con el cine en el aula. En I. Dussel y D. Gutiérrez (2006). Educar la mirada. Políticas y pedagogías de la imagen (pp. 135-144). Buenos Aires: Manantial.

Rancière, J. (2010). El espectador emancipado. Buenos Aires: Manantial.

Ricoeur, P. (2008). La memoria, la historia y el olvido. Buenos Aires: Fondo de Cultura Económica.

Ruiz, A. (2011). Nación, moral y narración. Imaginarios sociales en la enseñanza y el aprendizaje de la historia. Buenos Aires: Miño y Dávila.

Ruiz, A. y Prada, M. (2012). La formación de la subjetividad política. Propuestas y recursos para el aula. Buenos Aires: Paidós.

Serra, M. (2004). El cine en la escuela. ¿Política o pedagogía de la mirada? En I. Dussel y D. Gutiérrez (2006). Educar la mirada. Políticas y pedagogías de la imagen (pp. 145-154). Buenos Aires: Manantial.

Siede, I. (2010). Preguntas y problemas en la enseñanza de las ciencias sociales. En I. Siede (coord.), Ciencias sociales en la escuela. Criterios y propuestas para la enseñanza (pp. 269-294). Buenos Aires: Aique.

Támara, R. y Velasco, G. (2006). Aprender haciendo historia. Métodos y técnicas para la enseñanza de la historia. Bogotá: Universidad Distrital Francisco José de Caldas.

Traverso, E. (2012). La historia como campo de batalla. Interpretar las violencias del siglo xx. Buenos Aires: Fondo de Cultura Económica.

Vasco, C. et ál. (1999). El saber tiene sentido. Una propuesta de integración curricular. Bogotá: Cinep.

Vega, C. (2011). Potencialidades del uso de la prensa como recurso didáctico en la asignatura de Historia y Ciencias Sociales: análisis metodológico y crítico de tres guías de estudio. Tesis para optar al grado de Licenciado en Educación. Santiago de Chile: Universidad Academia de Humanismo Cristiano.

Viñao, A. (2002). Sistemas educativos, culturas escolares y reformas. Madrid: Morata. 